\title{
The use of habitat models in conservation of rare and endangered leafhopper species (Hemiptera, Auchenorrhyncha)
}

\author{
Barbara Strauss and Robert Biedermann* \\ Landscape Ecology Group, Institute of Biology and Environmental Sciences, University of Oldenburg, 26111 \\ Oldenburg, Germany; *Author for correspondence (e-mail: robert.biedermann@uni-oldenburg.de; phone: \\ +49-0-441-798-29-55; fax: +49-0-441-798-56-59)
}

Received 9 March 2005; accepted in revised form 17 June 2005

Key words: Auchenorrhyncha, Habitat models, Prediction, Urban brownfields, Verdanus bensoni

\begin{abstract}
For conservation of Auchenorrhyncha species, knowledge of their habitat requirements is essential. However, for most species there is no 'quantitative' knowledge that would allow e.g. spatially explicit predictions. Such predictions can be made by habitat models, which quantify the relationship between the environment and the occurrence of species. In two plot-based case studies - the endangered leafhopper Verdanus bensoni in mountainous grasslands and four endangered Auchenorrhyncha in urban brownfields - we used habitat models to quantify the habitat requirements of these five species and to exemplify their use for creating habitat suitability maps. In the first case study, the multivariate model showed that occurrence probabilities of the leafhopper $V$. bensoni increase with both decreasing nitrogen indicator values and decreasing tree cover. On urban brownfields, successional age was a driving factor for species' occurrence. Site age largely determines a range of vegetation characteristics, which, in multivariate models, often replaced the variable age. Internal validation showed the robustness of all models. The models allow predictions of habitat quality under different management regimes (e.g. response to fertilization or abandonment for $V$. bensoni or to different turnover rates on brownfield sites). We discuss the application of habitat models in the conservation of Auchenorrhyncha, especially the use of habitat suitability maps.
\end{abstract}

\section{Introduction}

In cultural landscapes, habitat quality for $\mathrm{Au}-$ chenorrhyncha is often determined by habitat management. In grasslands, management type and intensity (e.g. mowing, grazing, fertilization) are of great importance (Morris 1981; Sedlacek et al. 1988; Nickel and Hildebrandt 2003). For instance, intensively used grasslands may exhibit different plant species composition and vegetation structure than largely undisturbed ones. The presence of certain host plants is a major habitat requirement of many Auchenorrhyncha species. The actual quality of host plant patches may be largely determined by the amount, architecture and physiology of the host plant (e.g. Prestidge 1982; Moon et al. 2000). For many Auchenorrhyncha species, additional factors like vegetation structure, microclimate or landscape context may be relevant (e.g. Claridge 1986; Denno and Roderick 1991; Haynes and Cronin 2003).

For conservation of Auchenorrhyncha species, knowledge of their habitat requirements is essential. However, for most species there is no "quantitative' knowledge that would allow e.g. spatially explicit predictions. Nickel (2003) presents a 
comprehensive review of habitat requirements and host plants of Auchenorrhyncha species in Germany. However, the information is qualitative and descriptive rather than quantified. For instance, Neophilaenus minor is described as preferring 'sparse cover of vegetation'. Since exact figures are not provided it remains unclear whether the optimum is at $20 \%$ vegetation cover, or if $50 \%$ is still tolerated. For this reason, data-based predictions of habitat suitability, especially at the landscape level, are not feasible.

Such predictions can be made with habitat models. The aims of habitat models are twofold (e.g. Guisan and Zimmermann 2000; Scott et al. 2002). First, habitat models analyze and quantify the relationship between species' abundance or occurrence and habitat factors. Second, they yield predictions of species' abundance or occurrence given certain environmental conditions. The latter makes habitat models a potentially powerful tool in nature conservation: models are able to predict the probability of occurrence for sites or landscapes where species distribution data are not available (Wilson et al. 2005). They can also be used to assess the effects of land use changes or succession on habitat quality (Rudner et al. 2005). Habitat suitability maps which can be obtained from habitat models identify potential core habitats of species and form the basis for the planning of nature reserves (e.g. Cabeza et al. 2004). Such predictions of spatial distribution are essential, since conservation planning has to deal with the whole landscape (Wilson et al. 2005).

Here, we use presence-absence data of $\mathrm{Au}-$ chenorrhyncha species and environmental data to build habitat models based on logistic regression. In two case studies - the rare leafhopper Verdanus bensoni in mountainous grasslands and four endangered Auchenorrhyncha in urban brownfields - we (1) demonstrate the procedure of model building, including variable selection, classification and internal validation, (2) quantify habitat requirements of selected species, (3) exemplify the construction of habitat suitability maps, and (4) discuss the application of habitat models in the conservation of Auchenorrhyncha, especially rare and endangered species. Rare here is understood as locally restricted due to rare habitat; the species can well build up considerable densities in their habitats.

\section{Methods}

Study sites

Case study 1: Leafhopper Verdanus bensoni

The first case study investigated habitat requirements of the leafhopper Verdanus bensoni (China, 1933). It was conducted in the mountain ranges of Dreisessel (1332 m; 48 $\left.47^{\prime} \mathrm{N}, 13^{\circ} 48^{\prime} \mathrm{E}\right)$ and Arber $\left(1456 \mathrm{~m} ; 49^{\circ} 06^{\prime} \mathrm{N}, 13^{\circ} 08^{\prime} \mathrm{E}\right)$ in the Bavarian Forest, Germany. The climate is characterized by mean annual temperatures between 5 and $6{ }^{\circ} \mathrm{C}$ with annual precipitation between 900 (low altitudes) and $2000 \mathrm{~mm}$ (high altitudes). For details on climate, geology and soil types see Hofmann (1984). The area is largely covered by forests. While at altitudes up to approx. $1200 \mathrm{~m}$, mixed forests (mainly beech, fir and spruce) are predominant, above this altitude only spruce forests are found. In the valleys and at lower altitudes land use is characterized by a mix of forests, pastures and fields. At higher altitudes only few patches of grassland are scattered within the forests, mainly small pastures ('Schachten', see Hofmann 1984) and ski runs.

Verdanus bensoni has a scattered range and is restricted to European mountain ranges (Nickel 2003). Up to now, it has been recorded from the German Alps, Scottish Highlands, Swiss and French Jura, Bavarian and Bohemian Forest, Giant Mountains, and Ural Mountains. In Germany, Verdanus bensoni is a rare species in the Alps and the Bavarian Forest. It is listed in the Red Data Book (Remane et al. 1998). In the study area, the Bavarian Forest, $V$. bensoni was recorded above approx. $800 \mathrm{~m}$ a.s.l. (Biedermann unpubl.). $V$. bensoni was found in montane and alpine grasslands, probably feeding on grasses (Biedermann 1998; Nickel 2003). However, the specific habitat requirements have not been studied yet in detail.

\section{Case study 2: Endangered species in urban} brown-fields

The second case study was carried out on brownfield sites in the city of Bremen, located in the lowlands of northwest Germany $\left(8^{\circ} 44^{\prime} \mathrm{N}\right.$, $53^{\circ} 05^{\prime} \mathrm{E}$, mean temperature $8.8^{\circ} \mathrm{C}$, mean annual precipitation $694 \mathrm{~mm}$ ). Urban brownfields, previously-developed land within cities, often support a rich wildlife and house a whole range of rare and 
endangered species (Gibson 1998; Eyre et al. 2003). They can provide habitat for stenotopic species from semi-natural habitats like dry sandy grasslands (Eversham et al. 1996). Brownfields form highly dynamic habitats (Gibson 1998; Gilbert 1989) which are continuously being generated, quickly changed by successional processes and destroyed by redevelopment. We assume that, within this cycle, each species finds a limited period of time where its habitat requirements are met. In this study, we investigated four endangered species found on brownfield-sites: the leafhoppers Rhopalopyx vitripennis (Flor, 1861) and Macrosteles quadripunctulatus (Kirschbaum, 1868), the froghopper Neophilaenus minor (Kirschbaum, 1868) and the planthopper Kelisia sabulicola (W. Wagner, 1952). They are listed as 'threatened' or 'potentially threatened' ( $N$. minor) in Germany's Red Data Book (Remane et al. 1998).

\section{Sampling design}

Case study 1

For the Verdanus bensoni study, 42 plots $(5 \times 5 \mathrm{~m})$ were chosen at altitudes between $542 \mathrm{~m}$ and $1453 \mathrm{~m}$ a.s.l., depending on the availability of grasslands or forests with a grass layer. In each grassland or forest the plots were chosen randomly. In each plot the following parameters were measured: total plant cover and cover of the predominant grass species in the herb layer, tree cover, slope, and altitude. Additionally, the mean Ellenberg indicator values (Ellenberg et al. 1992) for moisture and nitrogen were calculated from the plant species composition. The occurrence of Verdanus bensoni was recorded by sweep-netting. At each plot, 20 sweeps were taken covering the entire plot. The sweep-netting was repeated three times.

\section{Case study 2}

We investigated urban brownfields within $77 \mathrm{~km}^{2}$ in the city of Bremen. On the brownfield sites, 157 sample plots of $225 \mathrm{~m}^{2}$ were set up in a random stratified way (Guisan and Zimmermann 2000; Hirzel and Guisan 2002; Maggini et al. 2002). Minimum distance between plots was set to $80 \mathrm{~m}$. To ensure that all characteristic types of brownfields got sampled, the plots covered three gradients: site size, age of brownfields (duration of abandonment) and soil moisture. In 2003, sweepnet sampling was carried out four times between early June and early September, with 100 sweeps each time.

At each study plot we collected a set of environmental parameters. These included several parameters describing vegetation structure, cover of host plants (as specified by Nickel 2003), soil parameters and landscape context. Site age, as time since demolition of buildings or any other severe disturbance that put succession back to zero, we derived from a time series of aerial photographs. Landscape context was assessed using a map of vegetation types. For examples of these vegetation types see Table 3 . Within a GIS, we calculated the proportion of each of these types within a certain distance around every plot (Strauß et al. 2004). We tested radii between 25 and $125 \mathrm{~m}$.

For detailed measurement of vertical vegetation structure, we used a white screen, divided in rectangles, that was erected perpendicular to the ground (see Sundermeier 1999). At six points per plot, vertical cover was estimated for each rectangle looking through a $10 \mathrm{~cm}$ wide stand of vegetation. From these estimates, height and density parameters were calculated (Table 3) (Sundermeier 1999; Zehm et al. 2003). 50\%-height refers to the height below which $50 \%$ of the total vegetation cover is located. $75 \%$-height and $90 \%$ height are defined respectively.

\section{Statistical methods of habitat modeling}

\section{Logistic regression}

We used species' presence/absence data for model building. A popular approach for modeling such data is using logistic regression (i.e. generalized linear models (GLM) with a logistic link) (Morrison et al. 1998; Guisan and Zimmermann 2000; Hosmer and Lemeshow 2000; Harrell 2001; Reineking and Schröder 2003). Logistic regression has been successfully used in numerous studies on habitat-occurrence relationships (e.g. Peeters and Gardeniers 1998; Guisan et al. 1999; Manel et al. 1999a). Metric variables can be handled along with nominal ones. The shape of the response curve can be either sigmoid or unimodal ('bell-shaped'), the latter by including second order terms (Peeters and Gardeniers 1998; Hosmer and Lemeshow 2000). The outcome of a logistic regression model is the 
occurrence probability at given parameter values. To distinguish between predicted presence and absence, a threshold probability needs to be defined. Predictions should stay restricted to the range of parameter values that has been covered by the study.

\section{Measures of model performance}

Numerous measures assessing performance of logistic regression models are available (Hosmer and Lemeshow 2000; Pearce and Ferrier 2000a; Manel et al. 2001). All of them can only describe certain aspects of model performance. Therefore, we used a set of criteria, threshold-independent as well as threshold-dependent (Manel et al. 1999b).

The difference between predicted and observed values (model calibration) was measured by $R^{2}{ }_{N}$ (Nagelkerke 1991). Like $R^{2}$ in linear regression, it ranges from 0 to 1 . On an univariate level, we used $R_{N}^{2}$ to compare the relative influence that single predictor variables had on species' presence. Model discrimination was assessed with AUC (Hanley and McNeil 1982), the Area Under the receiver operating characteristic Curve (AUC). AUC values $\geq 0.7$ are regarded as acceptable, $\geq 0.8$ as excellent, and $\geq 0.9$ as outstanding (Hosmer and Lemeshow 2000).

Sensitivity (proportion of correctly predicted presences), specificity (proportion of correctly predicted absences) and CCR (correct classification rate) are classification threshold dependent measures. CCR is easy to interpret, however largely dependent on the rather arbitrary choice of a threshold (Reineking and Schröder 2003) and should be handled with care. As a threshold, we chose $\mathrm{P}_{\text {fair }}$, where specificity and sensitivity are equivalent (Hosmer and Lemeshow 2000). Since the species under study are rare and their prevalence is low, $\mathrm{P}_{\text {fair }}$ ensures that a reasonable proportion of presences will be predicted correctly. On the other hand, this may result in a lower total number of correct predictions (lower CCR) and, in particular, more predicted presences for observed absences (lower specificity) than with other thresholds. For nature conservation, where often the aim will be to correctly predict as many relevant habitats patches as possible (Morrison et al. 1998), we believe that the advantages of $P_{\text {fair }}$ outrun these disadvantages.

Since CCR, sensitivity and specificity are highly dependent on the species' prevalence (Manel et al.
2001), we used Cohen's Kappa $\kappa$ (Cohen 1960) as another, less sensitive threshold-dependent measure (Fielding and Bell 1997). Kappa ranges from 0 to 1 with values between 0.40 and 0.55 indicating fair agreement and values between 0.55 and 0.70 indicating good agreement between observed and predicted values (Monserud and Leemans 1992). For comparison between models we used the information criterion $\mathrm{AIC}_{\mathrm{c}}$, a version of $\mathrm{AIC}$ (Akaike's Information Criterion) modified for small samples (Buckland et al. 1997). AIC indicates how well a model performs the trade-off between model fit and model complexity.

\section{Model building}

As recommended by Hosmer and Lemeshow (2000), we performed careful univariate analyses prior to building of multivariate models. For each species, we tested univariate models of all variables. Only significant variables $(p \leq 0.05)$ with $R_{N}^{2} \geq 0.05$ were considered for further analysis.

A popular approach for building multivariate models uses stepwise procedures for variable selection. Pearce and Ferrier (2000b) recommend the stepwise backward procedure, which we used for the Verdanus bensoni study. In general, all stepwise procedures have some disadvantages (Reineking and Schröder 2004). They might not find the best model, or selection is unstable and does not hold for slightly different data. With a large number of predictor variables, like in the brownfield study, stepwise procedures perform poorly. Therefore, in that study, we followed a different approach: we calculated models for all combinations of four, three and two parameters, using Splus 6.1 functions glm and stepAIC (MASS library). Since the ratio 'number of observations'/ 'predictor variables' should not fall much below 10 (Morrison et al. 1998; Guisan and Zimmermann 2000), more than four variables per model are not a sound choice for the available data sets.

Strong correlations between predictor variables will lead to abnormally high coefficients and standard errors (Neter et al. 1989). Therefore, maximum spearman rank correlation $\left(r_{\mathrm{S}}\right)$ between predictor variables within one model was allowed to be 0.7 (Fielding and Haworth 1995). Since height and density parameters in the brownfield study showed strong correlations, only one of each group was chosen for multivariate modeling. 
Model validation

Performance criteria are usually over-optimistic if they are calculated on the same data set that was used for parameter estimation (Reineking and Schröder 2003). Since independent data were not available to correct for this optimism, we used the bootstrap as an internal validation method (Verbyla and Litaitis 1989; Efron and Tibshirani 1993) for evaluating the models. According to Steyerberg et al. (2001) and Harrell (2001), it outperforms other internal validation procedures and allows nearly unbiased estimates of model performance. We performed the bootstrap with Splus 6.1, doing 300 iterations, resulting in corrected measures of model performance.

\section{Habitat suitability maps}

Habitat suitability maps can be obtained by applying the regression equations of habitat models to maps of the relevant environmental data within a GIS. These maps spatially explicitly predict the probability of occurrence of the focal species (Osborne et al. 2001; Austin 2002; Joy and Death 2004). Models used for such spatially explicit predictions are restricted to parameters that are available area-wide. In the brownfield-study, these were age of brownfield sites, and all landscape context parameters. For N. minor, we calculated a model from these parameters and applied it to part of the study area.

\section{Results}

\section{Univariate models}

\section{Case study 1}

The univariate logistic regression analysis revealed that a number of significant habitat parameters were related to the incidence of Verdanus bensoni (Table 1). The occurrence of $V$. bensoni was positively related to altitude and moisture indicator and negatively to nitrogen indicator and tree cover. The habitat parameters slope and total plant cover showed no effect on the occurrence of $V$. bensoni. Likewise, the cover of single grass species had no positive influence on the occurrence of $V$. bensoni.

Case study 2

For the brownfield study, univariate responses for all relevant variables are listed in Table 3. A total of 29 predictor variables passed the performance criteria. Age was a strong predictor for all four species. M. quadripunctulatus showed a sigmoid response, occurrence probability decreasing with increasing age (Figure 2), whereas the other species showed unimodal responses with peaks between 13 and 20 years.

Vegetation height did not play an important role for $M$. quadripunctulatus. K. sabulicola, $N$. minor and $R$. vitripennis showed similar, mostly unimodal responses to vegetation height and density parameters. $R$. vitripennis made an exception in preferring high density in the lowest layer. For M. quadripunctulatus, high overall density decreased occurrence probability, whereas it preferred moderate densities within the lower vegetation layers.

Most species exhibited strong relationships with moss cover, litter cover and bare ground. As with density and height, $K$. sabulicola was negatively correlated with moss and litter cover, whereas the other species preferred medium to high values for these parameters. In general, high covers of the respective host plants strongly enhanced occurrence probabilities. PH was the most important amongst the soil parameters. M. quadripunctulatus preferred high, whilst $N$. minor and $R$. vitripennis preferred medium levels.

Overall, the influence of landscape context was comparatively weak with two exceptions. Occurrence of $N$. minor increased with rising proportions of brownfields with grassy, sparse vegetation. $M$. quadripunctulatus showed an unimodal response to the proportion of open brownfields with $<10 \%$ vegetation cover. For all species, $R^{2}{ }_{N}$ of landscape context was highest for the $75 \mathrm{~m}$-radius.

Table 1. Case study 1: Univariate responses of the leafhopper Verdanus bensoni to various habitat parameters.

\begin{tabular}{lllc}
\hline Parameter & Range & \multicolumn{2}{l}{$\begin{array}{l}\text { Response of } \\
V . \text { bensoni }\end{array}$} \\
\hline Altitude & $542-1453 \mathrm{~m}$ & 0.43 & $+\mathrm{S}$ \\
Nitrogen indicator & $2-6$ & 0.41 & $-\mathrm{S}$ \\
Moisture indicator & $5-7$ & 0.34 & $+\mathrm{S}$ \\
Tree cover & $0-100 \%$ & 0.14 & $-\mathrm{S}$ \\
\hline
\end{tabular}

$-\mathrm{S}$ : sigmoid response, occurrence probability decreases with increasing values of predictor variable; $+\mathrm{S}$ : sigmoid, occurrence probability increases with increasing values of predictor variable. 


\section{Multivariate models}

\section{Case study 1}

The multivariate habitat model for $V$. bensoni contained two significant habitat parameters (Table 2). The model showed that with both decreasing nitrogen indicator values and decreasing tree cover the incidence of $V$. bensoni increased (Figure 1). Model discrimination was good (Table 2): in $85 \%$ of the plots occurrence of $V$. bensoni was correctly classified.

\section{Case study 2}

The final multivariate models for the brownfield species contained three or four ( $N$. minor) explanatory variables (Table 3). Model performance measures are given in Table 5, coefficients, standard errors and $p$-values in Table 4.

The model for $R$. vitripennis included the parameters age, moss cover and cover of Festuca rubra/ovina. Occurrence probabilities were highest at medium levels of age and moss cover (Figure 3 ). With increasing cover of Festuca, the influence of these parameters became negligible; occurrence probabilities always exceeded the threshold.

Occurrence of $N$. minor could be explained best with a four-parameter model. Occurrence probabilities above the threshold were restricted to low, but non-zero $50 \%$-heights, regardless of the other parameter values (Figure 4). Moderate litter covers were preferred in combination with low cover of Corynephorus canescens and low proportions of

Table 2. Case study 1: Multiple habitat model of the leafhopper Verdanus bensoni.

\begin{tabular}{ll}
\hline Model parameters \& coefficients & \\
Nitrogen indicator & -1.94218 \\
Tree cover & -0.05667 \\
Intercept & 7.33042 \\
& \\
Model performance & $p<0.001$ \\
Significance & 0.56 \\
$R^{2}{ }_{\text {Ncorr }}$ & 0.88 \\
$\mathrm{AUC}_{\text {corr }}$ & \\
Classification $\mathrm{P}_{\text {fair }}$ & \\
$\mathrm{P}_{\text {fair }}$ & 0.48 \\
$\kappa$ & 0.72 \\
Sensitivity & 0.88 \\
Specificity & 0.85 \\
CCR & 0.85
\end{tabular}

Model parameters, model performance and classification using the threshold $\mathrm{P}_{\text {fair }}$.

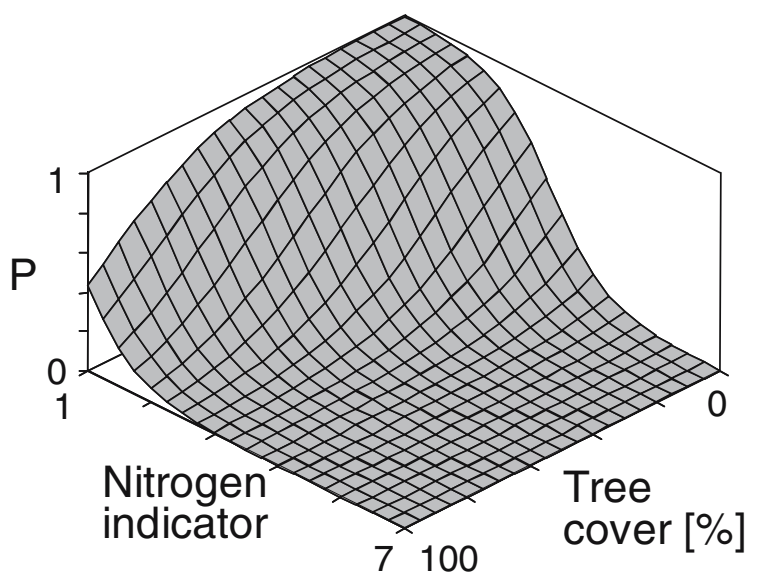

Figure 1. Multiple habitat model for Verdanus bensoni. Probability of occurrence $(\mathrm{P})$ is plotted against nitrogen indicator and tree cover.

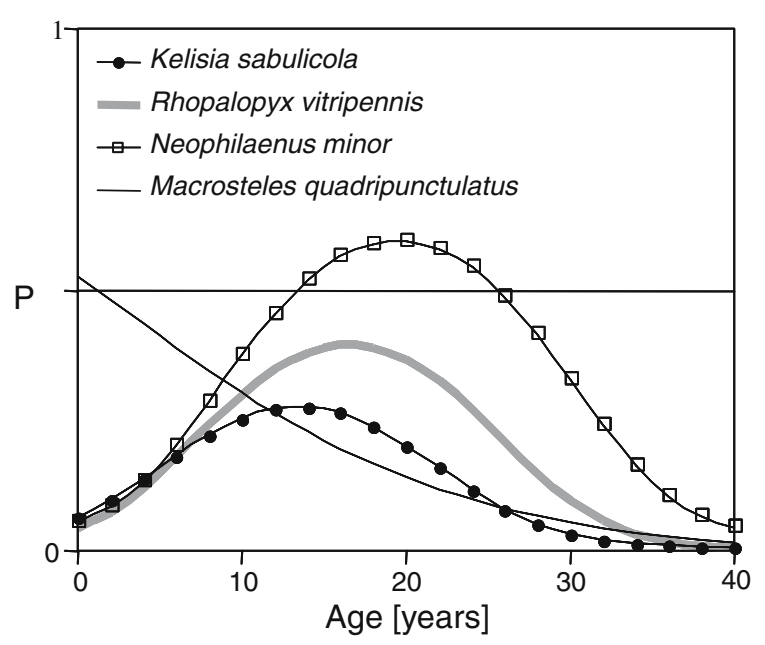

Figure 2. Univariate response curves for the variable 'age'.

BGS75. With increasing values of either or both of these parameters, the modifying influence of litter cover decreased. M. quadripunctulatus reached high occurrence probabilities only at moderate to high $\mathrm{pH}$-levels and in combination with both little to no litter cover and medium proportions of BO75 (Figure 6). The shape of the response surface of Kelisia sabulicola strongly depended on the cover of Carex arenaria. High values of $10 \%$ led to occurrence probabilities close to one, regardless of the other two factors (Figure 5). At low cover of Carex, presence depended on medium levels of age and vegetation density in the $0-5 \mathrm{~cm}$ layer. Model performance was better for $R$. vitripennis, $N$. minor and $M$. quadripunctulatus $\left(R_{N}^{2}>0.41\right.$, AUC 
Table 3. Case study 2: Univariate responses: $R^{2}{ }_{N}$ and shape of response curves. $R^{2}{ }_{N}$ of variables included in best multiple models printed bold.

\begin{tabular}{|c|c|c|c|c|c|c|c|c|c|}
\hline \multirow{3}{*}{$\begin{array}{l}\text { Variable/Parameter } \\
\text { Age [years] }\end{array}$} & \multirow{3}{*}{$\begin{array}{l}\text { Range } \\
0-33\end{array}$} & \multirow{2}{*}{\multicolumn{2}{|c|}{$\frac{M . \text { quad. }}{R_{N}^{2}}$}} & \multirow{2}{*}{\multicolumn{2}{|c|}{$\frac{K . \text { sabul. }}{R_{N}^{2}}$}} & \multirow{2}{*}{\multicolumn{2}{|c|}{$\frac{N . \text { minor }}{R_{N}^{2}}$}} & \multirow{2}{*}{\multicolumn{2}{|c|}{$\begin{array}{l}R . \text { vitrip. } \\
R_{N}^{2}\end{array}$}} \\
\hline & & & & & & & & & \\
\hline & & 0.16 & $-\mathrm{S}$ & 0.13 & $\mathrm{U}$ & 0.19 & $\mathrm{U}$ & 0.21 & $\mathrm{U}$ \\
\hline \multicolumn{10}{|l|}{ Vegetation height $[\mathrm{cm}]$} \\
\hline Veg. height & $0-110$ & & & & & & & 0.22 & $\mathrm{U}$ \\
\hline Weighted height & $0-24$ & & & 0.09 & $\mathrm{U}$ & 0.10 & $\mathrm{U}$ & 0.18 & $\mathrm{U}$ \\
\hline Max. height & $0-117$ & & & 0.05 & $+\mathrm{S}$ & & & 0.20 & $\mathrm{U}$ \\
\hline $50 \%$-height & $0-10$ & & & & & 0.14 & $\mathrm{U}$ & & \\
\hline $75 \%$-height & $0-28$ & & & & & 0.11 & $\mathrm{U}$ & 0.08 & $\mathrm{U}$ \\
\hline $90 \%$-height & $0-63$ & & & 0.06 & $\mathrm{U}$ & & & 0.13 & $\mathrm{U}$ \\
\hline \multicolumn{10}{|l|}{ Vegetation density [\%] } \\
\hline Veg. cover (horizontal) & $0-90$ & 0.05 & $-\mathrm{S}$ & 0.14 & $\mathrm{U}$ & & & 0.22 & $\mathrm{U}$ \\
\hline Veg. density (vertical) & $0-21$ & 0.08 & $-\mathrm{S}$ & & & & & 0.22 & $\mathrm{U}$ \\
\hline Veg. dens. $0-5 \mathrm{~cm}$ & $0-92$ & 0.16 & $\mathrm{U}$ & 0.14 & $\mathrm{U}$ & 0.07 & $\mathrm{U}$ & 0.18 & $+\mathrm{S}$ \\
\hline Veg. dens. $5-15 \mathrm{~cm}$ & $0-66$ & 0.14 & $\mathrm{U}$ & 0.13 & $\mathrm{U}$ & 0.07 & $\mathrm{U}$ & & \\
\hline Veg. dens. $15-50 \mathrm{~cm}$ & $0-28$ & 0.06 & $-\mathrm{S}$ & & & & & 0.13 & $\mathrm{U}$ \\
\hline Veg. dens. $50-100 \mathrm{~cm}$ & $0-20$ & & & & & & & 0.07 & $\mathrm{U}$ \\
\hline Density variation & $0-7$ & & & & & & & 0.11 & $\mathrm{U}$ \\
\hline \multicolumn{10}{|l|}{ Other vegetation parameters [\%] } \\
\hline Moss cover & $0-100$ & 0.23 & $-\mathrm{S}$ & 0.05 & $+\mathrm{S}$ & 0.05 & $+\mathrm{S}$ & 0.23 & $\mathrm{U}$ \\
\hline Litter cover & $0-100$ & 0.27 & $-\mathrm{S}$ & & & 0.08 & $\mathrm{U}$ & 0.18 & $+\mathrm{S}$ \\
\hline Bare ground & $0-100$ & 0.20 & $\mathrm{U}$ & 0.12 & $-\mathrm{S}$ & 0.06 & $-\mathrm{S}$ & 0.18 & $-\mathrm{S}$ \\
\hline \multicolumn{10}{|l|}{ Cover of host plants [\%] } \\
\hline Festuca rubra/ovina & $0-88$ & & & & & 0.05 & $+\mathrm{S}$ & 0.40 & $+\mathrm{S}$ \\
\hline Carex arenaria & $0-19$ & & & 0.20 & $+\mathrm{S}$ & & & & \\
\hline Corynephorus canescens & $0-38$ & & & & & 0.29 & $+\mathrm{S}$ & & \\
\hline \multicolumn{10}{|l|}{ Soil } \\
\hline Effective cation exchange capacity & $2-15$ & & & 0.09 & $\mathrm{U}$ & & & 0.07 & $\mathrm{U}$ \\
\hline $\mathrm{pH}$ & $3.4-7.7$ & 0.24 & $+\mathrm{S}$ & & & 0.18 & $\mathrm{U}$ & 0.12 & $\mathrm{U}$ \\
\hline Stone content (topsoil) & $0-6$ & 0.08 & $+\mathrm{S}$ & 0.07 & $\mathrm{U}$ & 0.17 & $-\mathrm{S}$ & & \\
\hline Available water capacity & $4-193$ & & & & & 0.08 & $+\mathrm{S}$ & 0.05 & $+\mathrm{S}$ \\
\hline \multicolumn{10}{|c|}{ Landscape context: Proportion of brownfields, covered with a certain structural vegetation type, within a radius of $75 \mathrm{~m}$ [\%] } \\
\hline Open ( $<10 \%$ veg. cover) ('BO75’) & $0-100$ & 0.14 & $\mathrm{U}$ & & & & & 0.05 & $-\mathrm{S}$ \\
\hline Grassy, sparse veg. ('BGS75’) & $0-100$ & & & 0.07 & $+\mathrm{S}$ & 0.36 & $+\mathrm{S}$ & & \\
\hline Grassy, dense veg. & $0-82$ & 0.06 & $-\mathrm{S}$ & & & & & 0.07 & $\mathrm{U}$ \\
\hline Herbaceous, sparse veg. & $0-98$ & 0.09 & $\mathrm{U}$ & & & & & 0.06 & $-\mathrm{S}$ \\
\hline Bushes/hedges & $0-22$ & & & & & & & 0.08 & $\mathrm{U}$ \\
\hline
\end{tabular}

-S: sigmoid response, occurrence probability decreases with increasing values of predictor variable; + S: sigmoid, occurrence probability increases with increasing values of predictor variable; U: unimodal response.

$>0.84)$ than for K. sabulicola $\left(R^{2}{ }_{N}=0.29\right.$, AUC $=0.77$, Table 3).

\section{Habitat suitability map}

The habitat suitability map for $N$. minor (Figure 8) was based on a two-parameter model with age and BGS75. Occurrence probability steeply rose with increasing proportions of BGS75, in particular in combination with medium age (Figure 7). As the threshold was low (0.13), most of the response surface was above the threshold. Nevertheless, large proportions of the brownfield sites (62\%) have low values for BGS75 combined with young age, resulting in occurrence probabilities below the threshold, shown as white regions on the map. The model yielded poorer performance than the best 
model for the species (Table 5), with $R^{2}{ }_{N}$ at 0.38 and AUC at 0.83 . Sensitivity and specificity were at 0.76 and 0.77 , respectively. Out of the 28 plots within the section shown in the map (Figure 8), all nine presences were predicted correctly, six of the 19 absences were classified incorrectly as presences.

\section{Discussion}

\section{Case study 1}

For $V$. bensoni, the most important habitat factor was found to be the fertility of the grassland sites. $V$. bensoni was restricted to low productivity sites. Consequently, agricultural intensification and fertilization of the low productivity habitats would pose a threat to $V$. bensoni. Further, the occurrence of $V$. bensoni would decrease if the tree cover of grassland sites increased, for instance, after abandonment of mowing or grazing. There was no relationship between the occurrence of $V$. bensoni and the cover of single grass species. It was known from literature that $V$. bensoni lives on grasses and it has been argued that $V$. bensoni may use several grass species as host plants (Biedermann 1998; Nickel 2003). Our results confirm that $V$. bensoni obviously is not a host plant specialist like, for instance, Neophilaenus minor.

\section{Case study 2}

Within our dataset, age of brownfield sites was the most driving factor determining species' occurrence. This agrees with the results of Small et al. (2003) for carabid assemblages, who found that time since the last disturbance has a significant influence on species' occurrence. In the study by Brown et al. (1992), successional age had a strong effect on leafhopper assemblages. Characteristic stages of brownfield succession strongly depend on time (Gilbert 1989), but substrate can modify succession rates considerably (Gilbert 1989; Small et al. 2003). The main difference between successional stages lies in their vegetation structures (Hollier et al. 1994). This might be the reason why in two of the 'best' multivariate models, age was substituted by vegetation parameters. They prob- 
Table 5. Case study 2: Coefficients and $p$-values of the multiple models.

\begin{tabular}{|c|c|c|c|}
\hline & Coeff. & S.E. & $p$ \\
\hline \multicolumn{4}{|c|}{ Macrosteles quadripunctulatus } \\
\hline Intercept & -5.09507 & 1.32829 & $<0.01$ \\
\hline $\mathrm{BO} 75$ & 0.04916 & 0.03337 & 0.14 \\
\hline $\mathrm{BO} 75^{\wedge} 2$ & -0.00080 & 0.00040 & 0.04 \\
\hline Litter & -0.03818 & 0.00997 & $<0.01$ \\
\hline $\mathrm{ph}$ & 0.87389 & 0.21201 & $<0.01$ \\
\hline \multicolumn{4}{|l|}{ Rhopalopyx vitripennis } \\
\hline Intercept & -3.97124 & 0.74998 & $<0.01$ \\
\hline Age & 0.20959 & 0.11836 & 0.08 \\
\hline $\mathrm{Age}^{\wedge} 2$ & -0.00703 & 0.00346 & 0.04 \\
\hline Moss.cover & 0.09384 & 0.03630 & 0.01 \\
\hline Moss.cover ${ }^{\wedge} 2$ & -0.00101 & 0.00040 & 0.01 \\
\hline Festuca rubra/ovina & 0.06775 & 0.01595 & $<0.01$ \\
\hline \multicolumn{4}{|l|}{ Neophilaenus minor } \\
\hline Intercept & -9.80625 & 3.26620 & $<0.01$ \\
\hline $50 \%$-height & 3.18859 & 1.65463 & 0.05 \\
\hline $50 \%$-height ${ }^{\wedge} 2$ & -0.48593 & 0.22308 & 0.03 \\
\hline Litter cover & 0.14831 & 0.04900 & 0.00 \\
\hline Litter cover ${ }^{\wedge} 2$ & -0.00140 & 0.00052 & 0.01 \\
\hline Corynephorus canescens & 0.23070 & 0.11937 & 0.05 \\
\hline BGS75 & 0.06173 & 0.01633 & $<0.01$ \\
\hline \multicolumn{4}{|c|}{ Neophilaenus minor (suitability map) } \\
\hline Intercept & -3.40644 & 0.57092 & $<0.01$ \\
\hline Age & 0.06440 & 0.02664 & 0.02 \\
\hline $\mathrm{Age}^{\wedge} 2$ & -0.00197 & 0.00122 & 0.11 \\
\hline BGS75 & 0.05627 & 0.01057 & $<0.01$ \\
\hline \multicolumn{4}{|l|}{ Kelisia sabulicola } \\
\hline Intercept & -4.61357 & 0.95524 & $<0.01$ \\
\hline Age & 0.20585 & 0.10274 & 0.05 \\
\hline $\mathrm{Age}^{\wedge} 2$ & -0.00432 & 0.00292 & 0.14 \\
\hline Veg.dens. $0-5 \mathrm{~cm}$ & 0.10049 & 0.04486 & 0.03 \\
\hline Veg.dens. $0-5 \mathrm{~cm}^{\wedge} 2$ & -0.00117 & 0.00051 & 0.02 \\
\hline Carex arenaria & 0.64897 & 0.24579 & 0.01 \\
\hline
\end{tabular}

ably represent the specific conditions of a particular site more accurately.

Vegetation structure is known to strongly affect species composition of Auchenorrhyncha communities (Murdoch et al. 1972; Denno and Roderick 1991; Achtziger 1995). We assume that vegetation structure is also an indirect measure for a site's microclimate. Sparse vegetation causes more extreme conditions in terms of temperature and moisture (Biedermann 1997, Geiger et al. 2003). Soil conditions influence both plant species composition and food quality of plants (Schoonhoven et al. 1998). The effect of soil conditions on Auchenorrhyncha was shown by Sanderson et al. (1995).

Landscape context we believe to indirectly represent several factors. First, it is a measure for site isolation. If proportions of favored habitat types are low or those of unsuitable habitat are high, the site is likely to be isolated and thus less likely to be occupied (Haynes and Cronin 2003; Biedermann 2004). Second, landscape context is an indicator for patch size: large proportions of favorable habitat types represent large patch sizes. Large patches have a higher probability of being occupied (e.g. Biedermann 2002). The positive correlation between $N$. minor and proportion of brownfields with grassy, sparse vegetation is probably due to either of these two factors. Third, surrounding vegetation influences a site's microclimate. Bushes and hedges slow down wind and thus provide more balanced, warmer and moister conditions. Sparse vegetation does the opposite. The comparatively small influence of landscape 


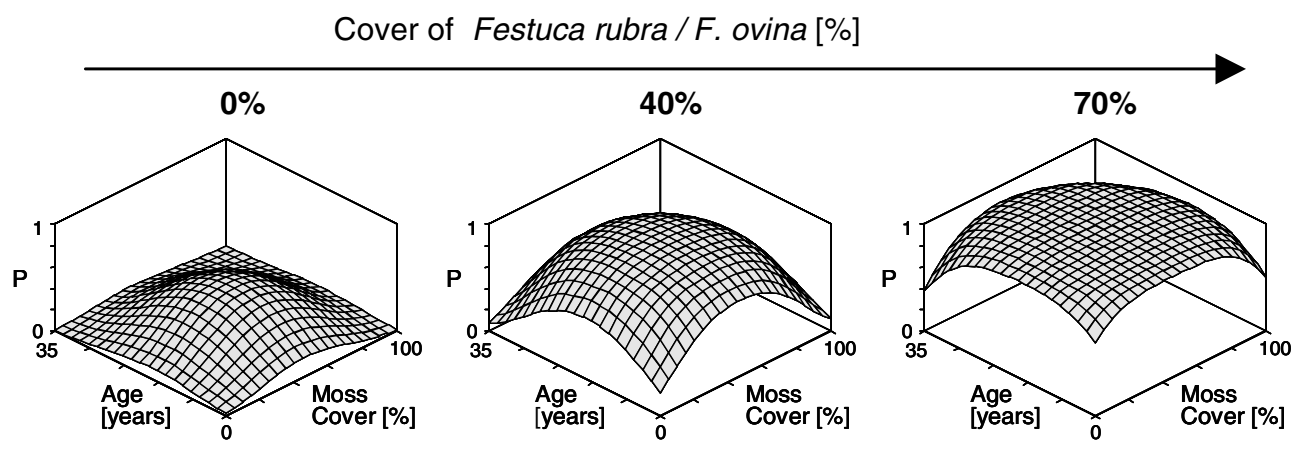

Figure 3. Best habitat model for Rhopalopyx vitripennis. Occurrence probability $(\mathrm{P})$ on the z-axis, against age and moss cover. Three levels of Festuca rubra/ovina-cover are represented in the three diagrams.

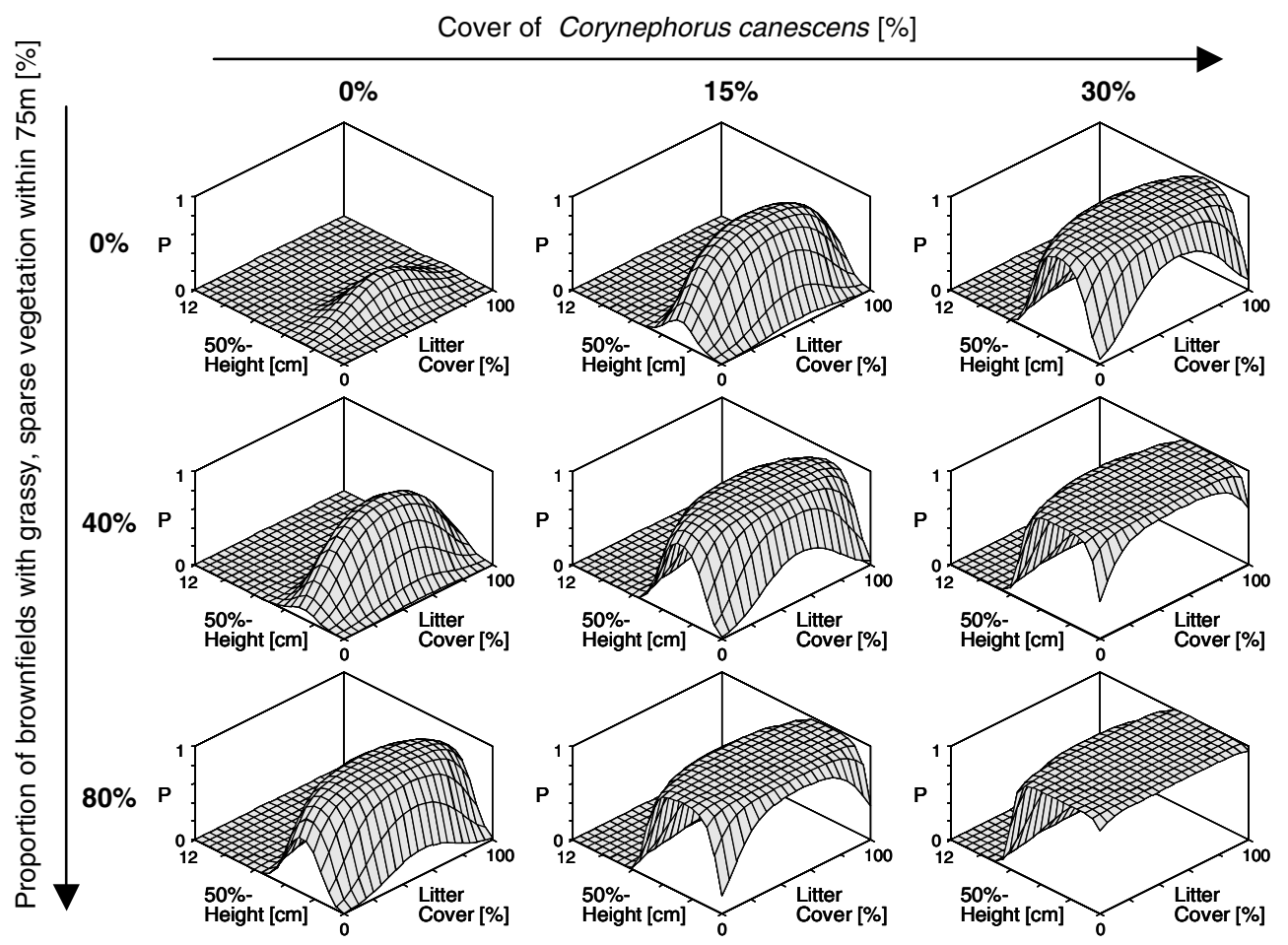

Figure 4. Best habitat model for Neophilaenus minor. In each diagram, P is plotted against 50\%-Height and litter cover. Columns represent different levels of Corynephorus canescens-cover and rows represent different proportions of BGS75.

context might be due to two factors. First, most Auchenorrhyncha species seem to not need large sites to build up viable populations (Biedermann 2002, 2004; Cronin 2004). Second, it is likely that for Auchenorrhyncha, most brownfield sites are not truly isolated. Small patches of potential habitat are found along most roads and tracks and connect the larger sites.
Overall, univariate responses of all four species corresponded well to habitat requirements described in Nickel (2003). For instance, $M$. quadripunctulatus is regarded as a pioneer species preferring sandy, sparsely vegetated and moderately dry to dry sites. This agrees with our results that the species was restricted to young sites with very scarce vegetation. 


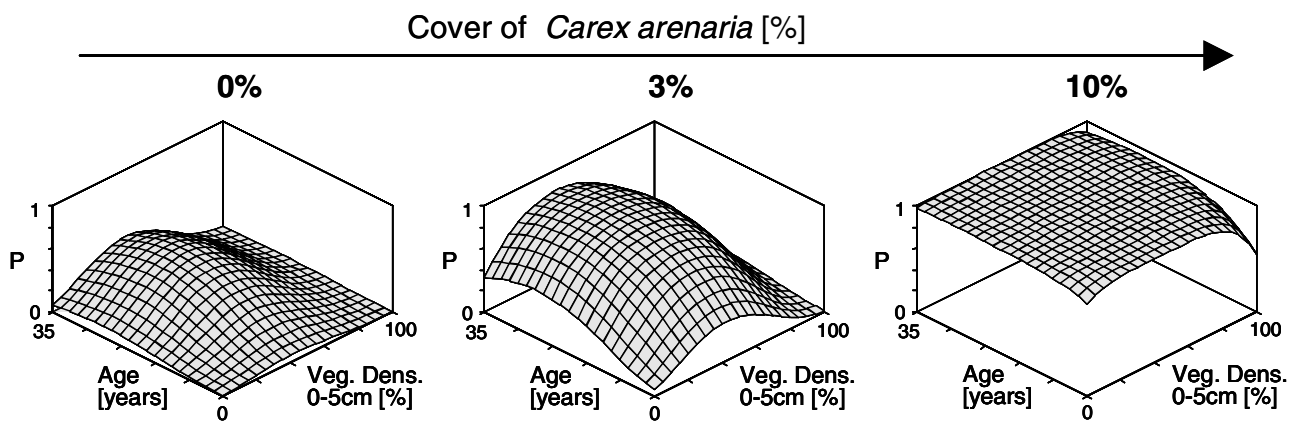

Figure 5. Best habitat model for Kelisia sabulicola. $\mathrm{P}$ is plotted against age and vegetation density $0-5 \mathrm{~cm}$; diagrams represent different levels of Carex arenaria cover.

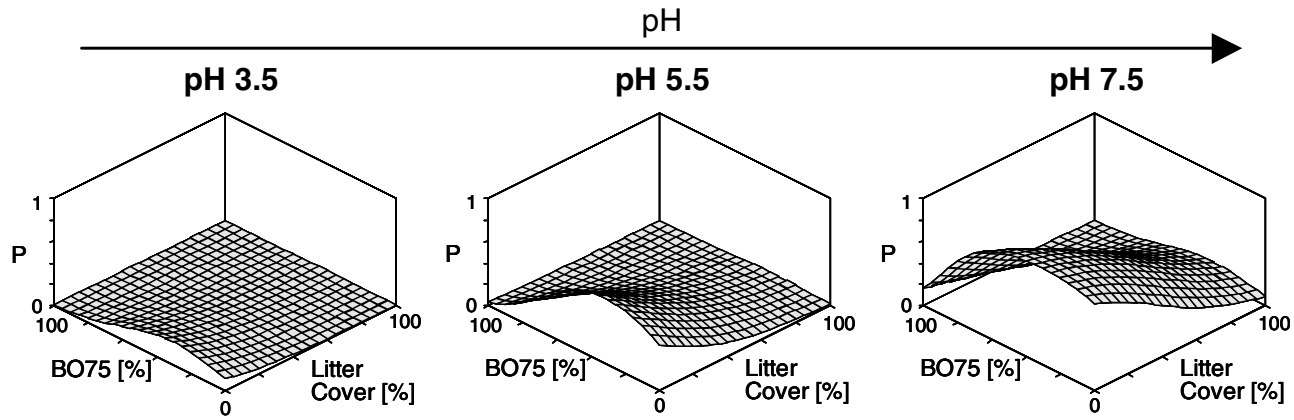

Figure 6. Best habitat model for Macrosteles quadripunctulatus. P plotted against BO75 and litter cover; diagrams represent different levels of $\mathrm{pH}$.

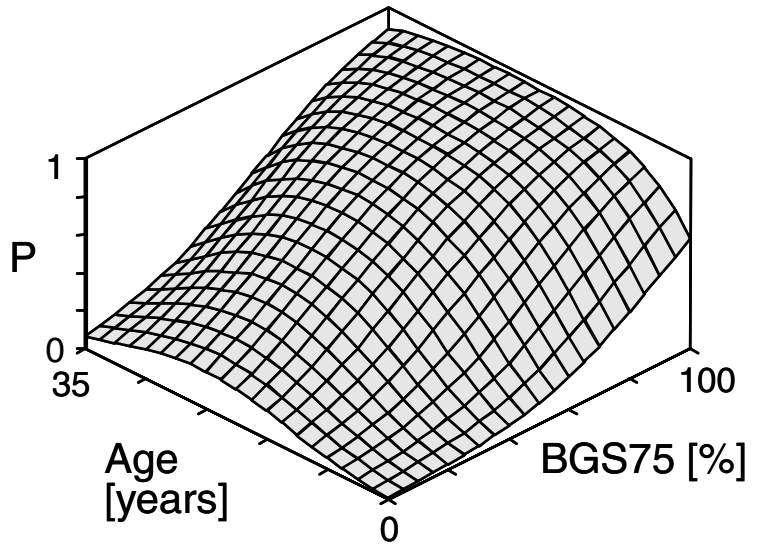

Figure 7. Model used to calculate a habitat suitability map for Neophilaenus minor. P plotted against age and BGS75.

The use of habitat models in conservation

Internal validation showed the robustness of habitat models within our studies. However, in perspective, it would be desirable to validate these models externally, i.e. apply them to independent data sets from other landscapes. In this respect, it would be interesting to test whether the habitat model of Verdanus bensoni from the Bavarian Forest is applicable to Alpine populations. The transfer of habitat models has been successfully demonstrated in other insects (Kuhn and Kleyer 1999/2000; Schröder and Richter 1999/2000; Bonn and Schröder 2001; Binzenhöfer et al. 2005). Unfortunately, up till now there have been no attempts with Auchenorrhyncha. However, transferability is regarded as a prerequisite for the broad application of habitat models in the conservation of Auchenorrhyncha.

The habitat models presented here are able to predict the quality of habitats under different management. In the leafhopper Verdanus bensoni, the habitat model predicts the response to fertilization or abandonment. In the urban brownfield study, the effects of different turnover rates became obvious. Models are able to predict the occurrence of species along a temporal gradient of 


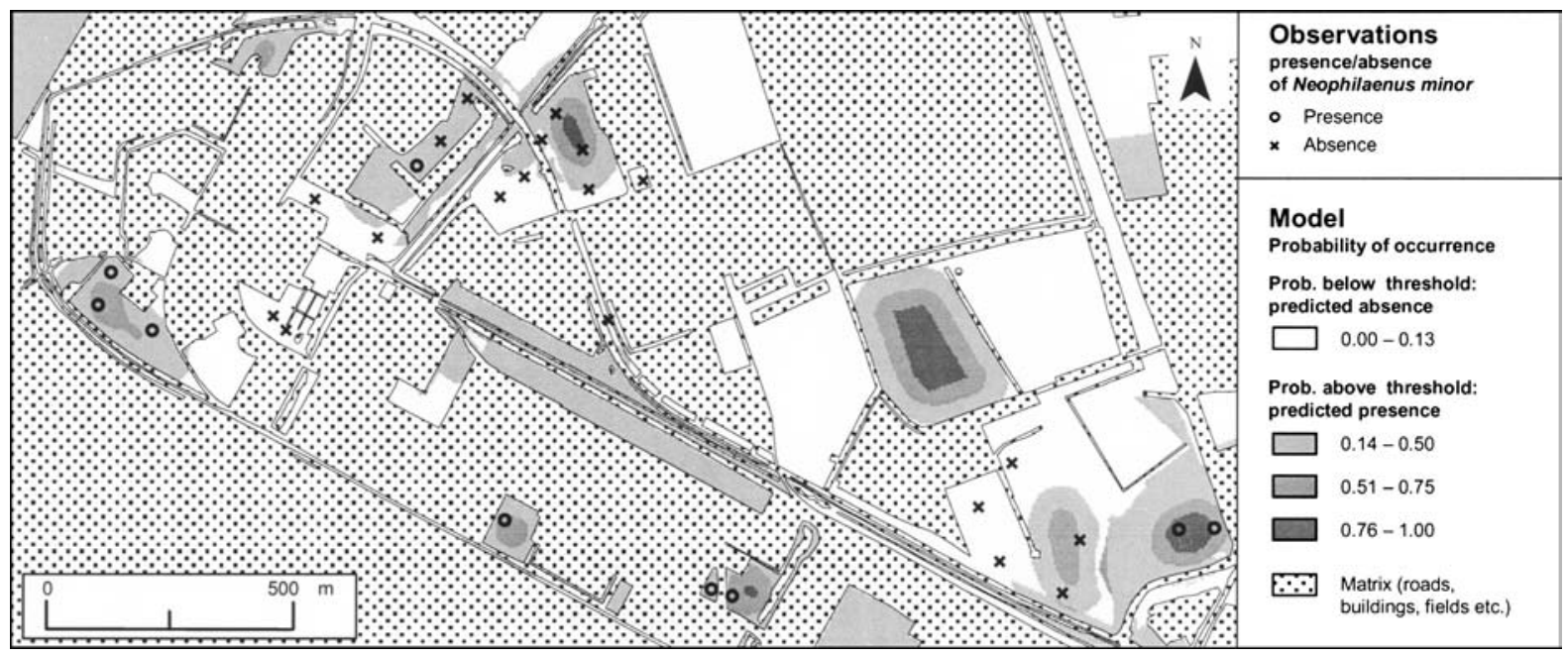

Figure 8. Habitat suitability map for Neophilaenus minor. Non-brownfield sites (sealed areas: e.g. roads, buildings, container parks; farmland: mostly wet grassland) are considered per se as unsuitable habitats (matrix) and dotted on the map.

succession. This quantitative information may be essential for the conservation of species in brownfields. It was shown that the species under study are restricted to the early or intermediate stages of brownfield succession. Once sites become too old, these species are likely to disappear. Small et al. (2003) found for carabid beetles that the most species rich assemblages are found on early successional sites that can be between 6 and 20 years old. For conservation, this implies that protection of existing brownfield-sites without management will cause many species to disappear over time. In order to preserve high biodiversity, one should focus on the duration of the brownfield stage within the cycle of emergence, succession and demolition of brownfields sites. A constant stock of brownfields of young and intermediate age within an industrial area preserves the typical species assemblage.

The case studies also showed that in some species it is possible to build habitat models with good performance using only a few habitat parameters. For instance, in Verdanus bensoni two parameters were sufficient to reach a high correct classification rate. For conservation purpose, those habitat models may be a tool to identify potential habitat relying on only a small number of environmental parameters. Even though a large number of parameters might be necessary to detect the driving forces and build well performing models, once these parameters are known, models can easily be applied to other regions, assuming the availability of data for the parameters. In the light of increasing availability of area-wide environmental data (e.g. from satellite imagery or public GIS databases) this prerequisite will be easier to meet in future. However, some variables, like the ones describing aspects of vegetation structure in a detailed way, can not be obtained area-wide by these methods. Still, these variables are of great importance when studying a species' ecological needs. Hence, for habitat suitability maps, these variables have to be substituted by ones that are available area-wide. The application of habitat suitability maps in conservation may easily identify and map areas for protection (e.g. Cabeza et al. 2004). However, there are some issues to consider when applying habitat models and habitat suitability maps. First, species' absences can never be recorded with the same certainty as species' presences. Kleyer et al. (1999/2000) suggest regarding presence and absence as a species-specific characteristic. Second, false-positive predictions do not necessarily indicate a poor model fit, since plots recorded as non-use are not always unsuitable habitat (Capen et al. 1986). This is particularly true in declining populations, where many falsepositive predictions might result (Wilson et al. 2005): due to an increased extinction rate, suitable habitat might not be inhabited. Thus, habitat suitability maps may help to identify areas for the 
reintroduction of endangered or rare species by showing potentially suitable habitat.

In conclusion, this study demonstrated the building and application of habitat models for Auchenorrhyncha. Although further research is needed, especially on the generality of single species habitat models, the value of habitat models for conservation seems obvious. The use of habitat suitability maps could find broad application in future.

\section{Acknowledgements}

The brownfield case study is part of the TEMPOproject and was financially supported by the German Ministry of Education and Research (BMBF, grant 01LM0210). We thank Ute Schadek for providing soil data for the brownfield study. The manuscript was improved by helpful comments of two anonymous referees.

\section{References}

Austin M.P. 2002. Spatial prediction of species distribution: an interface between ecological theory and statistical modelling. Ecol. Model. 157: 101-118.

Achtziger R. 1995. Die Struktur von Insektengemeinschaften an Gehölzen: Die Hemipteren-Fauna als Beispiel für die Biodiversität von Hecken und Waldrandökosystemen. Bayreuther Forum Ökologie (bfö) 20: 1-216.

Biedermann R. 1997. Populationsökologische Untersuchungen an Zikaden (Homoptera, Auchenorrhyncha): zum Einfluß von Habitatqualität, Habitatgröße und Isolation auf das Vorkommen und Überleben von Populationen. University of Mainz, Mainz, PhD thesis.

Biedermann R. 1998. Erstnachweis der Zwergzikade Verdanus bensoni (China, 1933) (Homoptera, Auchenorrhyncha, Cicadellidae) für Deutschland. Entomolog. Nachr. Ber. 42: 83.

Biedermann R. 2002. Leafhoppers (Hemiptera, Auchenorrhyncha) in fragmented habitats. Denisia 4: 523-530.

Biedermann R. 2004. Patch occupancy of two hemipterans sharing a common host plant. J. Biogeogr. 31: 1179-1184.

Binzenhöfer B., Schröder B., Strauss B., Biedermann R. and Settele J. 2005. Habitat models and habitat connectivity analysis for butterflies and burnet moths - the example of Zygaena carniolica and Coenonympha arcania. Biol. Conserv, In press.

Brown V.K., Gibson C.W.D. and Kathirithamby J. 1992 Community organization in leaf hoppers. Oikos 65: 97-106.

Bonn A. and Schröder B. 2001. Habitat models and their transfer for single- and multi species groups: a case study of carabids in an alluvial forest. Ecography 24: 483-496.

Buckland S.T., Burnham K.P. and Augustin N.H. 1997. Model selection: an integral part of inference. Biometrics 53: 603-618.
Buckland S.T. and Elston D.A. 1993. Empirical models for the spatial distribution of wildlife. J. Appl. Ecol. 30: 478-495.

Cabeza M., Araújo M.B., Wilson R.J., Thomas C.D., Cowley M.J.R. and Moilanen A. 2004. Combining probabilities of occurrence with spatial reserve design. J. Appl. Ecol. 41: 252262.

Capen D.E., Fenwick J.W., Inkley D.B. and Boynton A.C. 1986. Multivariate models of songbird habitat in New England forests. In: Verner J., Morrison M.L. and Ralph C.J (eds), Wildlife 2000: Modeling Habitat Relationships of Terrestrial Vertebrates. University of Wisconsin Press, Madison, pp. 171-177.

Claridge D.W. 1986. The distribution of a typhlocybine leafhopper, Ribautiana ulmi (Homoptera, Cicadellidae) on a specimen wych elm tree. Ecol. Entomol. 11: 31-39.

Cohen J. 1960. A coefficient of agreement for nominal scales. Educat. Psychol. Measure 30: 37-46.

Cronin J.T. 2004. Host-parasitoid extinction and colonization in a fragmented landscape. Oecologia 139: 503-514.

Denno R.F. 1994. Influence of habitat structure on the abundance and diversity of planthoppers. In: Denno R.F. and Perfect T.J. (eds), Planthoppers - Their Ecology and Management. Chapman \& Hall, London, pp. 140-160.

Denno R.F. and Roderick G.K. 1991. Influence of patch size, vegetation texture, and host plant architecture on the diversity, abundance, and life history styles of sap-feeding herbivores. In: Bell S.S., McCoy E.D. and Mushinsky H.R. (eds.), Habitat structure: The Physical Arrangement of Objects in Time and Space. Chapman and Hall, London, pp. 169-196.

Efron B. and Tibshirani R.J. 1993. An Introduction to the Bootstrap. Chapman and Hall, New York.

Ellenberg H., Weber H.E., Düll R., Wirth W., Werner W. and Paulißen D. 1992. Zeigerwerte von Pflanzen in Mitteleuropa. Verlag Erich Goltze, Göttingen.

Eversham B.C., Roy D.B. and Telfer M.G. 1996. Urban, industrial and other manmade sites as analogues of natural habitats for Carabidae. Ann. Zool. Fenn. 33: 149-156.

Eyre M.D., Luff M.L. and Woodward J.C. 2003. Beetles (Coleoptera) on brownfield sites in England: an important conservation resource? J. Insect Conserv. 7: 223-231.

Fielding A.H. and Bell J.F. 1997. A review of methods for the assessment of prediction errors in conservation presence-absence models. Environ. Conserv. 24: 38-49.

Fielding A.H. and Haworth P.F. 1995. Testing the generality of bird-habitat models. Conserv. Biol. 9: 1466-1481.

Geiger R., Aron R.H. and Todhunter P. 2003. The Climate near the Ground. Rowman and Littlefield, Lanham.

Gibson C.W.D. 1998. Brownfield: Red Data - The Values Artificial Habitats Have for Uncommon Invertebrates. English Nature Research Reports, 273

Gilbert O.L. 1989. The Ecology of Urban Habitats. Chapman and Hall, London.

Guisan A., Weiss S.B. and Weiss A.D. 1999. GLM versus CCA spatial modeling of plant species distribution. Plant Ecol. 143: $107-122$.

Guisan A. and Zimmermann N.E. 2000. Predictive habitat distribution models in ecology. Ecol. Model. 135: 147-186.

Hanley J.A. and McNeil B.J. 1982. The meaning and use of the area under a ROC curve. Radiology 143: 29-36. 
Harrell F.E. 2001. Regression Modeling Strategies. Springer, New York.

Haynes K.J. and Cronin J.T. 2003. Matrix composition affects the spatial ecology of a prairie planthopper. Ecology 84: 2856-2866.

Hirzel A. and Guisan A. 2002. Which is the optimal sampling strategy for habitat suitability modeling. Ecol. Model. 157: 329-339.

Hofmann A. 1984. Magerrasen im Hinteren Bayerischen Wald. Hoppea 44: 85-177.

Hollier J.A., Brown V.K. and Edwards-Jones G. 1994. Successional leafhopper assemblages: pattern and process. Ecol. Res. 9: 185-191.

Hosmer D.W. and Lemeshow S. 2000. Applied Logistic Regression. Wiley, New York.

Joy M.K. and Death R.G. 2004. Predictive modelling and spatial mapping of freshwater fish and decapod assemblages using GIS and neural networks. Freshwat. Biol. 49: 1036-1052.

Kleyer M., Kratz R., Lutze G. and Schröder B. 1999/2000. Habitatmodelle für Tierarten: Entwicklung, Methoden und Perspektiven für die Anwendung. Z. Ökol. Natursch. 8: 177194.

Kuhn W. and Kleyer M. 1999/2000. A statistical habitat model for the Blue Winged Grasshopper (Oedipoda caerulescens) considering the habitat connectivity. Z. Ökol. Natursch. 8: 207-218.

Maggini R., Guisan A. and Cherix D. 2002. A stratified approach for modeling the distribution of a threatened ant species in the Swiss National Park. Biodivers. Conserv. 11: $2117-2141$.

Manel S., Dias J.M., Buckton S.T. and Ormerod S.J. 1999a. Alternative methods for predicting species distribution: an illustration with Himalayan river birds. J. Appl. Ecol. 36: 734-747.

Manel S., Dias J.-M. and Ormerod S.J. 1999b. Comparing discriminant analysis, neural networks and logistic regression for predicting species distributions: a case study with a Himalayan river bird. Ecol. Model. 120: 337-348.

Manel S., Williams H.C. and Ormerod S.J. 2001. Evaluating presence-absence models in ecology: the need to account for prevalence. J. Appl. Ecol. 38: 921-931.

Monserud R.A. and Leemans R. 1992. Comparing global vegetation maps with Kappa statistic. Ecol. Model. 62: 275-293.

Moon D.C., Rossi A.M. and Stiling P. 2000. The effects of abiotically induced changes in host plant quality (and morphology) on a salt marsh planthopper and its parasitoid. Ecol. Entomol. 25: 325-331.

Morris M.G. 1981. Responses of grassland invertebrates to management by cutting. III. Adverse effects on Auchenorrhyncha. J. Appl. Ecol. 18: 107-123.

Morrison M.L., Marcot B.G. and Mannan R.W. 1998. Wildlife-habitat Relationships - Concepts and Applications. The University of Wisconsin Press, Madison, Wisconsin.

Murdoch W.M., Evans F.C. and Peterson C.H. 1972. Diversity and patterns in plants and insects. Ecology 53: 819-829.

Nagelkerke N.J.D. 1991. A note on a general definition of the coefficient of determination. Biometrika 78: 691-692.

Neter J., Wasserman W. and Kutner M.H. 1989. Applied Linear Regression Models. Richard D. Irwin Burr Ridge, Boston, Sydney.
Nickel H. 2003. The Leafhoppers and Planthoppers of Germany (Hemiptera, Auchenorrhyncha), Patterns and strategies in a highly diverse group of phytophagous insects. Series Faunistica 28. Pensoft, Sofia.

Nickel H. and Hildebrandt J. 2003. Auchenorrhyncha communities as indicators of disturbance in grasslands (Insecta, Hemiptera) - a case study from the Elbe flood plains (Northern Germany). Agric. Ecosyst. Environ. 98: 183-199.

Osborne P.E., Alonso J.C. and Bryant R.G. 2001. Modelling landscape-scale habitat using GIS and remote sensing: a case study with great bustards. J. Appl. Ecol. 38: 458-471.

Pearce J. and Ferrier S. 2000a. Evaluating the predictive performance of habitat models developed using logistic regression. Ecol. Model. 133: 224-245.

Pearce J. and Ferrier S. 2000b. An evaluation of alternative algorithms for fitting species distribution models using logistic regression. Ecol. Model. 128: 127-147.

Peeters E.T.H.M. and Gardeniers J.J.P. 1998. Logistic regression as a tool for defining habitat requirements of two common gammarids. Freshwat. Biol. 39: 605-615.

Prestidge R.A. 1982. Instar duration, adult consumption oviposition and nitrogen utilization efficiencies of leafhoppers feeding on different quality food (Auchenorrhyncha: Homoptera). Ecol. Entomol. 7: 91-101.

Reineking B. and Schröder B. 2003. Computer intensive methods in the analysis of species-habitat relationships. In: Reuter H., Breckling B. and Mittwoll A. (eds), GfÖ Arbeitskreis Theorie in der Ökologie 2003: Gene, Bits und Ökosysteme. P. Lang Verlag, Frankfurt/M, pp. 165-182.

Reineking B. and Schröder B. 2004. Variablenselektion. In: Dormann C.F., Blaschke T., Lausch A., Schröder B. and Söndgerath D. (eds), Habitatmodelle - Methodik, Anwendung, Nutzen. Tagungsband zum Workshop vom 8.-10. Oktober 2004 am UFZ Leipzig, UFZ-Berichte 9/2004, pp. $39-45$.

Remane R., Achtziger R., Fröhlich W., Nickel H. and Witsack W. 1998. Rote Liste der Zikaden (Homoptera, Auchenorrhyncha). In: Dormann M., Bliss R., Boye P., Gruttke H. and Pretscher P. (eds.), Rote Liste der gefährdeten Tiere Deutschlands. Schriftenreihe für Landschaftspflege und Naturschutz pp. 55:234-245.

Rudner M., Biedermann R., Schröder B. and Kleyer M. 2005. Integrated Grid Based Ecological and Economic (INGRID) Landscape Model - a tool to support landscape management decisions. Environ. Modell. Softw, in press.

Sanderson R.A., Rushton S.P., Cherill A.J. and Byrne J.P. 1995. Soil, vegetation and space: an analysis of their effects on the invertebrate communities of a moorland in north-east England. J. Appl. Ecol. 32: 506-518.

Schoonhoven L.M., Jermy T. and van Loon J.J.A. 1998. Insect-Plant Biology. Chapman and Hall, London.

Schröder B. and Richter O. 1999/2000. Are habitat models transferable in space and time? Z. Ökol. Natursch 8: 195-205.

Scott J.M., Heglund P.J., Morrison M. and Haufler J.B. 2002. Predicting Species Occurrences: Issues of Accuracy and Scale. Island Press, Washington.

Sedlacek J.D., Barrett G.W. and Shaw D.R. 1988. Effects of nutrient enrichment on the Auchenorrhyncha (Homoptera) in contrasting grassland communities. J. Appl. Ecol. 25: 537550 . 
Small E.C., Sadler J.P. and Telfer M.G. 2003. Carabid beetle assemblages on urban derelict sites in Birmingham, UK J. Insect Conserv. 6: 233-246.

Steyerberg E.W.S., Harrell F.E., Borsboom G.J.J.M., Eijkemans M.J.C., Vergouve Y. and Habbema J.D.F. 2001. Internal validation of predictive models: Efficiency of some procedures for logistic regression analysis. J. Clin. Epidemiol. 54: 774-781.

Strauß B., Biedermann R. and Binzenhöfer B. 2004. Landschaftskontext in Habitatmodellen am Beispiel von Coenonympha arcania. In: Dormann C.F., Blaschke T., Lausch A., Schröder B. and Söndgerath D. (eds), Habitatmodelle - Methodik, Anwendung, Nutzen. Tagungsband zum Workshop vom 8.-10. UFZ-Berichte. pp. 83-85, Oktober 2004 am UFZ Leipzig, UFZ-Berichte 9/2004.
Sundermeier A. 1999. Zur Vegetationsdichte der Xerothermrasen nordwestlich von Halle/Saale. J.Cramer, Berlin \& Stuttgart.

Verbyla D.L. and Litaitis J.A. 1989. Resampling methods for evaluation of classification accuracy of wildlife habitat models. Environ. Manage. 13: 783-787.

Wilson K.A., Westphal M.I., Possingham H.P. and Elith J. 2005. Sensitivity of conservation planning to different approaches to using predicted species distribution data. Biol. Conserv. 122: 99-112.

Zehm A., Nobis M. and Schwabe A. 2003. Multiparameter analysis of vertical vegetation structure based on digital imaging processing. Flora 198: 142-160. 